\title{
TLR-mediated miR-125b-5p downregulation enhances CD248-induced metastasis and drug resistance in colorectal cancer cells
}

\section{GA-BIN PARK}

Kosin University College of Medicine

Daejin Kim ( $\nabla$ kimdj@inje.ac.kr)

Inje University College of Medicine https://orcid.org/0000-0001-7707-7688

\section{Research article}

Keywords: CD248, SP1, miR-125b-5p, Colorectal cancer, chemoresistance

Posted Date: June 20th, 2019

DOI: https://doi.org/10.21203/rs.2.10556/v1

License: (c) (i) This work is licensed under a Creative Commons Attribution 4.0 International License.

Read Full License 


\section{Abstract}

Background CD248, also called endosialin or tumor endothelial marker-1 (TEM1), is markedly upregulated in almost all cancers, including colon cancers. Changes in microRNA (miRNA) profiles are one of the direct causes of cancer development and progression. In this study, we investigated whether a change in CD248 expression in colon cancer cells could induce drug resistance after chemotherapy, and we explored the relationship between miR-125b-5p levels and CD248 expression in Toll-like receptor (TLR)modified chemoresistant colon cancer cells. Methods We identified the one of the downregulated miRNAs in drug-resistant HCT8 cells using Affymetrix Genechip miRNA 4.0 array process and validated the expressional change of chemoresistant HCT-116 and HT-29 cells. Interaction between Sp1 and miR-125b$5 p$ was confirmed by miScript target protector assay. To characterize the underlying mechanisms involved in CD248 expression, we adapted the several biological analysis techniques, including RNAbinding Protein Immunoprecipitation (RIP), migration analysis, real-Time PCR, western blot analysis, and gene silencing using siRNA. Results TLR2/ 6 and TLR5 upregulation in drug-resistant colon cancer cells contributed to miR-125b-5p downregulation and Sp1-mediated CD248 upregulation via NF-KB activation. Exposure to specific TLR2/6 or TLR5 ligands enhanced the expression of mesenchymal markers as well as the migratory activity of oxaliplatin (Ox)- or 5-fluorouracil (5-Fu)-resistant colon cancer cells. The transfection of a synthetic miR-125b-5p mimic into chemoresistant cells prevented Sp1 and CD248 activation and significantly impaired invasive activity. Furthermore, Sp1 or CD248 gene silencing as well as miR-125b-5p overexpression markedly reversed drug resistance and inhibited epithelial-mesenchymal transition (EMT) in colon cancer cells. Conclusions Taken together, these results suggest that changes in miR-125b-5p levels play an important role in Sp1-mediated CD248 expression and the development of drug resistance in TLR-mutated colon cancer cells.

\section{Background}

CD248 (endosialin, tumor endothelial marker 1, TEM1) is ubiquitously detected during embryonic development, but its expression is gradually restricted to pericytes and bone marrow-derived mesenchymal stem cells in adults [1]. CD248 is frequently upregulated in neuroblastoma and mesenchymal sarcoma as well as in human carcinomas, including colorectal cancer and breast cancer $[2,3]$. CD248 is also strongly expressed in the angiogenic vasculature of all high-grade gliomas [4]. In TEM1 knockout mice, the growth and metastasis of orthotopically transplanted tumors are significantly suppressed. In addition, TEM1 knockout mice with tumors survive longer than wild-type mice [5]. However, in phase I clinical trials of MORAb-004, the first humanized monoclonal antibody directed against human CD248, tumor sizes were not significantly reduced in patients with colorectal cancer who were administered high doses of this drug [6]. Analysis of CD248 expression in colon cancer samples revealed that CD248 is expressed in the tumor stromal compartment but not in colon cancer cells [7, 8]. In addition, the regulation of CD248 expression in colon cancer remains controversial, and the unidentified regulatory pathway by which CD248 controls the development of drug resistance and metastasis in colon cancer is incompletely understood. 
MicroRNAs (miRNA), small noncoding RNAs, bind to the 3' untranslated region (3' UTR) of their messenger RNA (mRNA) targets for posttranscriptional gene regulation that inhibits translation or mRNA degradation [9-11]. Thus, changing the expression patterns of either oncogenes or tumor suppressor genes via miRNAs plays an important role in carcinogenesis. Alterations in circulating miRNA expression profiles are not only associated with abnormal cellular functions but also related to molecular markers used for the detection, prognosis, and treatment strategy determination of various diseases, including colon cancer $[12,13]$. Recent studies have revealed that many miRNAs have been strongly associated with colorectal cancer [12-15]. p53 mutations involved in chemoresistance and changes in associated miRNAs (e.g., miR-34, miR-192/215 and miR-26a) have been reported in over half of colorectal cancer patients [16]. Upregulated miR-125b is also associated with colon cancer development and poor prognosis through its direct binding to the 3' UTR of human p53 mRNA [17]. However, the effect of miR$125 \mathrm{~b}$ on drug resistance in colorectal cancer cells and the underlying mechanism by which miR-125b modulates CD248 expression still need to be investigated.

Specificity protein 1 (Sp1), a basic transcriptional regulator for numerous genes, is usually related to carcinogenesis $[18,19]$. Sp1 binding to the promoter region of the CD248 gene activates its expression under high cell density culture conditions $[18,20]$. According to the results of a miRNA microarray using chemoresistant colon cancer cells and a search using the web-based miRNA prediction software TargetScan (http://www.targetscan.org/), we found that Sp1 could be a target gene of miR-125b-5p. Despite the recognized connection between miR-125b-5p and Sp1, the precise role and relationship of CD248 and miR-125b-5p in drug-resistant cancer cells are largely unknown.

Toll-like receptors (TLRs) provide host protective roles by mediating the activation and recruitment of leukocytes to infected sites. Moreover, TLR stimulation with a specific ligand promotes cancer development [21]. In particular, TLR2 and TLR4 expression are closely related to colon carcinogenesis and poor clinical outcomes after diagnosis [22]. However, the modification and exact role of TLR expression in chemoresistant colon cancer cells remain undefined. Therefore, we attempted to identify alterations in TLR expression in 5-fluorouracil (5-Fu)- and oxaliplatin (Ox)-resistant colon cancer cells and to validate the functional relationship between TLR and miR-125b-5p. Furthermore, we investigated whether modulating miR-125b-5p regulates the aberrant expression of CD248 via binding to Sp1 in colon cancer cells with modified TLR expression.

\section{Methods}

\section{Cell lines and reagents}

Human colorectal carcinoma cell lines HCT116, HCT8, and HT29 were purchased from the American Type Culture Collection (Manassas, VA, USA). These cells were cultured in RPMI 1640 media (Corning Incorporated, Corning, NY, USA) containing $10 \%$ FBS (RMBIO, Missoula, MT, USA), glutamine, and antibiotics and incubated at $37^{\circ} \mathrm{C}$ in $5 \% \mathrm{CO}_{2}$. Lipopolysaccharide (LPS, a TLR4 ligand), flagellin (a TLR5 ligand), Ox, 5-Fu, and fibronectin were purchased from Sigma-Aldrich (St. Louis, MO, USA). FSL-1 (a TLR2 
and TLR6 ligand) was obtained from Invivogen (San Diego, CA, USA). Sp1 miScript target protector for miR-125b was purchased from Qiagen (Hilden, Germany). Bay 11-7082 (an NF-kB inhibitor) was obtained from Selleckchem (Houston, TX, USA).

\section{Cytotoxicity assay for $\mathrm{IC}_{50}$ determination and establishment of drug-resistant cell lines}

Cells $\left(2 \times 10^{4}\right.$ cells/well) in 96-well plates were exposed to various concentrations of Ox or 5-Fu for $24 \mathrm{~h}$. The inhibition rate of cell growth was measured using the following formula: inhibition rate $(\%)=[1$ $\mathrm{OD}_{570}$ (experiment group)/OD 570 (control group)] $\times 100$ [23]. Cytotoxicity curves were obtained using GraphPad software by plotting the measured cell viability (\%) indicated by Cell Counting Kit-8 (CCK-8) assays (Sigma-Aldrich; Merck KGaA). Based on the CCK-8 assay results, the $50 \%$ inhibitory concentration $\left(\mathrm{IC}_{50}\right)$ values for $\mathrm{Ox}$ and 5-Fu were evaluated and calculated (Supplemental Table 1). Next, to create colorectal cancer cell lines with stable chronic resistance to Ox or 5-Fu, HCT116, HCT8, and HT29 cells were exposed to an initial concentration of $\mathrm{Ox}$ or 5-Fu at $1 \mu \mathrm{M}$ in RPMI 1640 medium plus $10 \% \mathrm{FBS}$, as previously described with slight modifications [24]. When cells that survived Ox or 5-Fu treatment reached $70 \sim 90 \%$ confluency, they were subcultured twice a week to confirm their viability. Thereafter, the dose of Ox or 5-Fu was doubled in each surviving population and sequentially increased to $50 \mu \mathrm{M}$. All resistant cell lines maintained and experimented at $20 \mu \mathrm{M}$ Ox or 5-Fu in RPMI 1640 medium plus $10 \%$ FBS. Finally, the authenticity of the drug-resistant sublines was verified by short tandem repeat profiling according to the ANSI Standard (ASN-0002) from the ATCC Standards Development Organization (SDO).

\section{MicroRNA microarray assay}

Total RNA from Oxaliplatin- or 5-fluorouracil-resistant HCT8 was separated using the miRNeasy Mini Kit (Qiagen, CA, USA). RNA purity and integrity for analysis were measured by ND-1000 Spectrophotometer (NanoDrop, Wilmington, USA), Agilent 2100 Bioanalyzer (Agilent Technologies, Palo Alto, USA). The Affymetrix Genechip miRNA 4.0 array process was executed according to the manufacturer's protocol and previously described [25]. Briefly, biotin-tagged RNA of each sample by FlashTag ${ }^{\text {TM }}$ Biotin RNA Labeling Kit (Genisphere, Hatfield, PA, USA) was quantified, fractionated, and hybridized according to the standard procedures provided by the manufacture. After RNA-array hybridization, the chips were washed, stained, and then scanned with an Affymetrix GCS 3000 canner (Affymetrix, Santa Clara, California, United States). Signal values were compare and calculated with using the Affymetrix ${ }^{\circledR}$ GeneChip ${ }^{\mathrm{TM}}$ Command Console software (AGCC).

\section{Quantitative real-time polymerase chain reaction (qRT-PCR)}


Total RNA from cells was extracted using an RNeasy Mini Kit (Qiagen) according to the supplier's instructions. cDNA was synthesized from $2 \mu \mathrm{g}$ of purified total RNA using Accupower ${ }^{\circledR}$ RT premix (Bioneer, Daejeon, Korea) and an oligo(dT) primer (Bioneer, Daejeon, Korea). To evaluate miRNA levels, total RNA was isolated from cells using an miRNeasy Mini Kit (Qiagen). cDNA was synthesized with a Mir-XTM miRNA First-Strand Synthesis Kit (Clontech, Mountain View, CA, USA). The mRNA and miRNA levels were quantified using SYBR Green (Takara, Tokyo, Japan), an ABI7300 real-time PCR system (Applied Biosystems, Foster City, CA, USA), and specific primer sets for TLR2 (upstream primer, 5'-GGC CAG CAA ATT ACC TGT GTG; downstream primer, 5'-CCA GGT AGG TCT TGG TGT TCA), TLR4 (upstream

primer, 5'-CTG CAA TGG ATC AAG GAC CA; downstream primer, 5'-TCC CAC TCC AGG TAA GTG TT), TLR5 (upstream primer, 5'-CAT TGT ATG CAC TGT CAC TC; downstream primer, 5'-CCA CCA CCA TGA TGA GAG CA), TLR6 (upstream primer, 5'-TAG GTC TCA TGA CGA AGG AT; downstream primer, 5'-GGC CAC TGC AAA TAA CTC CG), CD248 (upstream primer, 5'-TGG TGC CAA CGT GTG TCT TTT; downstream primer, 5'AGC GAT AGC AGT CAG TGA TGC), Sp1 (upstream primer, 5'-GCG AGA GGC CAT TTA TGT GT; downstream primer, 5'-GGC CTC CCT TCT TAT TCT GG), and miR-125b-5p (5'-TCC CTG AGA CCC TAA CTT GTG A). A specific primer set for $\beta$-actin (upstream primer, 5'-ATC CAC GAA ACT ACC TTC AA; downstream primer, 5'-ATC CAC ACG GAG TAC TTG C) was used as internal control for mRNA, and U6 from the Mir-XTM miRNA First-Strand Synthesis Kit was used as a control for miRNA.

\section{RNA-binding Protein Immunoprecipitation (RIP) assay for miRNA}

The RIP assay kit for miRNA (MBL, Nagoya, Japan) was used to confirm between miR-125b-5p and Sp1 interaction by following the supplier's protocol. Briefly, anti-EIF2C2/AGO2 mouse monoclonal antibody (MBL) or mouse IgG2a isotype control (Invitrogen, Thermo Fisher Scientific, Waltham, MA, USA) were incubated with protein $\mathrm{G}$ beads (Santa Cruz Biotechnology, CA, USA) at $4{ }^{\circ} \mathrm{C}$ for $4 \mathrm{~h}$. The fresh cell extracts were immunoprecipitated with the antibody-immobilized protein $\mathrm{G}$ beads at $4{ }^{\circ} \mathrm{C}$ overnight. The immunoprecipitated protein were eluted by boiling with Laemmli sample buffer. The immunoprecipitated RNAs were seperated using the two-step method described in the supplier's recommendations. Sp1 and miR-125b-5p expression levels were examined after total RNA isolation from antibody-immobilized Protein G agarose bead-ribonucleoprotein (RNP) complexes by real-time PCR.

\section{Western blot analysis}

Harvested cells were lysed with NP-40 buffer (Elpis Biotech, Daejeon, Korea) supplemented with a protease inhibitor cocktail and phosphatase inhibitors (Sigma-Aldrich). Equally quantified proteins (10 $\mu \mathrm{g} /$ sample) according to the results from a BCA assay kit (Pierce, Rockford, IL, USA) were subsequently loaded onto SDS-PAGE gels. After electrophoresis, the proteins were transferred onto NC membranes (Millipore Corp., Billerica, MA, USA). The membranes were then blocked with $5 \%$ non-fat skim milk and probed with primary antibodies. The expression levels of the target proteins were determined using a 
chemiluminescence kit (Advansta Corp., Menlo Park, CA, USA) and an Amersham Imager 600 (GE Healthcare Life Sciences, Little Chalfont, UK). The expression levels of $\beta$-actin were established as a control.

\section{Small interfering RNA (siRNA) or micro RNA (miRNA) transfection}

Human TLR2-siRNA (5'-GGG CAG UCU UGA ACA UUU AUU-3'), TLR6-siRNA (5'-CCA GAA UCC AGU UCU CCG A-3'), TLR5-siRNA (5'-CUC GCU UGG AUC UAU CCA-3'), CD248-siRNA (5'-GCG AAC ACG AAU GUG UGG A-3'), Sp1-siRNA (5'-CAG AUA CCA GAC CUC UUC U-3'), and negative control siRNA (Cat. No. SN1001-CFG) were purchased from Bioneer. A mature miR-125b mimic and negative control miRNA mimic were designed and synthesized by Bioneer. The sequence of the miR-125b-5p mimic was 5 '-UCC CUG AGA CCC UAA CUU GUG-3', and the sequence of the miR-125b-5p inhibitor was 5'-UCC CUG AGA CCC UAA CUU GUG A-3'. Specific primers for the negative control miRNA mimic (Cat. No. SMC-2001) and negative control miRNA inhibitor (Cat. No. SMC-2101) were purchased from Bioneer. Transfection with $200 \mathrm{nM}$ siRNA or 200 nM miRNA using Lipofectamine RNAiMAX Reagent (Invitrogen, Carlsbad, CA, USA) was performed according to the supplier's instructions. The cells were used for further experiments at $48 \mathrm{~h}$ after transfection.

\section{Scratch assay and migration assay for detecting cancer cell invasion activity}

Cells were seeded onto a 6-well plate and allowed to grow to approximately $90 \%$ confluency. The cells were wounded with a $200-\mu \mathrm{l}$ plastic tip and then incubated in $5 \% \mathrm{CO}_{2}$ at $37^{\circ} \mathrm{C}$ for $24 \mathrm{~h}$. After $24 \mathrm{~h}$ incubation, the cells were checked, and images were taken under an inverted phase contrast microscope equipped with a camera at $\times 100$ magnification. According to the supplier's instructions, the migratory and invasive activities of cancer cells were determined using a CytoSelectTM tumor transendothelial migration assay kit (Cell Biolabs, Inc., San Diego, CA, USA) and a CultreCoat 96-well Medium BME Cell Invasion Assay Kit (R\&D Systems, Minneapolis, MN, USA), respectively. The relative fluorescence units (RFUs) of migrated cells were determined by a microplate reader. The relative invasion of cells was compared with the fluorescence intensity of calcein-AM stained invading cells measured by a microplate reader.

\section{Measurement of NF-KB translocation and NF-KB DNA-binding activity}

Nuclear and cytoplasmic fractions were prepared using a Nuclear/Cytosol Fractionation Kit (BioVision Inc., Mountain View, CA, USA) according to the instructions of the supplier. Briefly, harvested cells ( $2 \times$ $10^{6} /$ sample) were resuspended in cytosol extraction buffer $A$ and incubated for 10 min on ice. After mixing with cytosol extraction buffer $B$, the supernatants collected by centrifugation were designated 
cytosolic fractions, and the pellets were suspended in $100 \mu \mathrm{l}$ of nuclear extraction buffer mix and designated nuclear fractions. All samples were kept at $-80^{\circ} \mathrm{C}$ until use. To block NF-kB activity, cells were treated with Bay 11-7082 (an NF-kB inhibitor; $5 \mu \mathrm{M}$ ) for $8 \mathrm{~h}$ or $24 \mathrm{~h}$ before the designated experiments. The DNA-binding activity of NF-KB was measured as described previously [26] using an NF-kB p50/p65 Transcription Factor Assay Kit (Abcam, Cambridge, MA, USA) according to the manufacturer's instructions.

\section{Quantification of human cytokines by ELISA}

The concentrations of EMT-related cytokines (TGF- $\beta 1$, TNF- $\alpha$, VEGF, and IL-8) in the cell culture supernatants were measured as described previously [27] using single cytokine ELISA assay kits (R\&D Systems) according to the supplier's instructions.

\section{Analysis of apoptosis by flow cytometry}

The percentages of cells undergoing the apoptotic process were measured by flow cytometry with fluorescein isothiocyanate (FITC)-labeled annexin-V (BD Biosciences, San Diego, CA, USA) and 7-amino actinomycin D (7-AAD) (BD Biosciences). The cells were suspended in $100 \mu \mathrm{l}$ of $1 \times$ annexin- $V$ binding buffer, and FITC-conjugated annexin-V $(3 \mu \mathrm{l})$ and 7-AAD $(3 \mu \mathrm{l})$ were then added to the suspensions; the cells were kept at room temperature for $15 \mathrm{~min}$ in the dark. Finally, the stained cells were monitored by a BD Accuri ${ }^{\mathrm{TM}}$ C6 (BD Biosciences).

\section{Statistical analysis}

One-way analysis of variance (ANOVA) using SPSS version 24.0 statistical software (IBM Corp., Armonk, NY, USA) or Student's t-test was used for all statistical analysis. Data are presented as the mean \pm standard deviation (SD). Differences were determined to be statistically significant at $p<0.05$ and highly significant at $p<0.01$.

\section{Results}

TLR2/6 and TLR5-mediated NF-KB activation in drug-resistant colon cancer cells induces CD248 expression and promotes metastasis.

The TLR4-LPS interaction promotes MyD88 and NF-KB activation, resulting in liver metastasis and poor prognosis in colorectal cancer $[28,29]$ We found that chemoresistant colon cancer cells exhibit lower TLR4 expression and higher TLR2/6 and TLR5 expression than their parent cells (Fig. 1A). Ligation of 
TLR2/ 6 and TLR5 with specific ligands induced the expression of mesenchymal markers and drug resistance-related proteins (MDR1 and MRP1-3) in oxaliplatin-resistant (OxR)-HCT8 cells (Fig. 1B). In addition, stimulation with a TLR2/6 or TLR5 ligand promoted the migratory and invasive activity of OxRHCT 8 cells (Fig. 1C). Gene silencing of TLR2/6 and TLR5 with siRNA prevented the induction of Sp1 and CD248, expression of drug resistance-related proteins, and migratory or invasive activity of drug-resistant cancer cells (Fig. 1D and 1E). NF-KB activation leads to the expression of a variety of genes that are related to tumorigenesis or antitumor responses [30]. In drug-resistant colon cancer cells, NF-KB activity was enhanced (Fig. 1F), and the nuclear levels of the active NF-KB subunits $p 50$ and p52 were increased (Fig. 1G). In addition, phosphorylated p65 in the nucleus was upregulated (Fig. 1G). Targeted inhibition of NF-KB activity with Bay 11-7082 suppressed the expression of Sp1 and CD248 as well as the levels of mesenchymal markers (Fig. $1 \mathrm{H}$ ). These results suggest that enhanced TLR2/6- and TLR5-induced NF-KB activation in chemoresistant cancer cells plays an important role in the induction of Sp1 and CD248, the development of drug resistance, and the promotion of cancer metastasis.

\section{miR-125b-5p levels regulate CD248 expression and metastasis in TLR-modified colon cancer cells.}

Sp1 controls CD248 expression in cancer cells subjected to hypoxic conditions through the increased expression of the Ets-1 transcription factor [21]. We identified Sp1 as a putative target of miR-125b-5p through a bioinformatic search (TargetScan.org). LPS-mediated NF-KB activation decreases miR-125b-5p levels, resulting in the production of TNF-a [31]. The reduced miR-125b-5p expression in drug-resistant colon cancer cells (Fig. 2A and 2B) was upregulated by targeting NF-KB activity using Bay 11-7082 (Fig. 2C). To confirm the Sp1 binding to miR-125b-5p in drug-resistance colon cancer cells was performed ribonucleoprotein immunoprecipitation (RIP) for miRNA. From precipitated mRNA-miRNA complex the using antibody against eukaryotic translation initiation factor $2 \mathrm{C}$ (elF2C), we observed that resistance to anti-cancer drug in colon cancer cells not only enhanced the level of Sp1 mRNA compared to that of parent cells but also suppressed the level of miR-125b-5p (Fig. 2D). The amount of ribonucleoprotein complex in each sample was re-confirmed by immunoblot using anti-elF2C2 antibody detecting different epitope (Fig. 2E). Furthermore, the downregulation of TLR2/6 or TLR5 using siRNA further increased the expression of miR-125b-5p over that observed in drug-sensitive cancer cells (Fig. 2F). Since drug-resistant colon cancer cells transfected with the miR-125b-5p mimic showed reduced Sp1 and CD248 expression (Fig. 2G) and since the miR-125b-5p inhibitor significantly increased the migratory and invasive activities of HCT8 cells (Fig. $2 \mathrm{H}$ ), we next designed a miR-target protector to determine whether miR-125b-5p interferes specifically with the interactions of Sp1. miR-125b-5p mimic transfection successfully prevented TLR2/6- or TLR5-specific ligand-mediated upregulation of Sp1 and CD248 in OxR-HCT8 and FuR-HCT8 cells (Fig. 3A), whereas treating drug-resistant colon cancer cells with a target protector markedly prevented the downregulation of Sp1 and CD248 by the miR-125b-5p mimic (Fig. 3B). Furthermore, the Sp1-miR-125-5p protector efficiently inhibited the effect of the miR-125b-5p mimic, which blocked the expression of Sp1 and CD248 in drug-resistant colon cancer cells after stimulation with a TLR ligand (Fig. 3C and 3D). Transfection of the miR-125b-5p mimic not only attenuated the 
metastatic activity of drug-resistant colon cancer cells (Fig. 3E and 3F) but also inhibited the induction of mesenchymal markers and drug resistance-related proteins (Fig. 3G). These results suggest that changes in TLR-mediated miR-125b-5p downregulation in colon cancer cells are associated with Sp1 and CD248 expression as well as the development of drug resistance and metastasis.

\section{Increased CD248 expression modulates the metastasis of colon cancer cells with modified TLR expression.}

We next investigated whether Sp1 and CD248 modulate epithelial-mesenchymal transition (EMT) and whether enhanced CD248 expression plays an important role in promoting the migratory activity of chemoresistant colon cancer cells. As we expected, specific siRNA-mediated downregulation of CD248 had no effect on miR-125b-5p levels (Fig. 4A). Targeted Sp1 inhibition reduced CD248 levels, whereas CD248 gene silencing had no effect on Sp1 levels in chemoresistant colon cancer cells (Fig. 4B). In addition, Sp1 or CD248 knockdown failed to reduce the expression of TLR2/6 and TLR5 in drug-resistant colon cancer cells (Fig. 4B). Silencing Sp1 and CD248 using siRNA attenuated mesenchymal marker and drug resistance-related protein expression (Fig. 4C), migration or invasion activity (Fig. 4D), and EMTrelated cytokine secretion in OxR-HCT8 cells (Fig. 4E). In the following experiment, we investigated whether increased CD248 contributes to cancer cell metastasis by exposure to fibronectin, a known ligand of CD248. Stimulation with fibronectin upregulated the expression of mesenchymal markers (Fig. $5 \mathrm{~A}$ ) and the migratory activity of drug-resistant colon cancer cells (Fig. 5B). Furthermore, CD248 knockdown profoundly suppressed the migratory activity of drug-resistant colon cancer cells after stimulation with fibronectin (Fig. 5C). miR-125b-5p mimic transfection not only prevented the expression of mesenchymal markers (Fig. 5D) but also blocked the metastatic activity of fibronectin-treated chemoresistant HCT8 cells (Fig. 5E). In addition, exposure to fibronectin promoted the production of EMTrelated cytokines in drug-resistant cancer cells. Moreover, the miR-125b-5p mimic significantly reduced the secretion of EMT-related cytokines in OxR-HCT8 cells after stimulation with fibronectin (Fig. 5F). These results suggest that CD248 expression plays a key role in the metastasis of TLR-modified chemoresistant colon cancer cells.

\section{Reduced miR-125b-5p and increased CD248 expression levels promote the generation of chemoresistant colon cancer cells.}

To examine the potential role of miR-125b-5p and CD248 in the development of drug resistance, we transfected drug-resistant HCT8 cells with the miR-125b-5p mimic or inhibited the expression of CD248 using siRNA. Restoring the miR-125b-5p level promoted the apoptosis of drug-resistant HCT8 cells after treatment with $0 x$ or 5-Fu (Fig. 6A and 6B). In addition, CD248 or Sp1 knockdown efficiently increased the apoptotic death of chemoresistant colon cancer cells administered Ox or 5-Fu (Fig. 6C and 6D). These 
results suggest that miR-125b-5p-regulated CD248 expression contributes to the development of drug resistance in colon cancer cells.

\section{Discussion}

Although the level of CD248 (TEM1, endothelin) is high during the developmental stage, it almost disappears entirely at birth [32]. However, CD248 is particularly upregulated in tumor stromal cells, and the interaction between CD248 on cancer-associated fibroblasts and malignant cells is an important mechanism for tumor development and promotes the migration and metastasis of cancer cells [33, 34]. In addition, the upregulation of CD248 in cancer tissue is highly related to tumor grade, invasiveness, and overall survival rate in colon cancer patients [35]. However, the expression and role of CD248 in colon cancer are not fully understood due to changes in pathological conditions. TLR4 is increased in all tumor components, including cancer cells and stromal fibroblasts, as well as in a variety of colon cancer cell lines [36]. Increased TLR4 and IL-6 expression is associated with colorectal cancer development, and the activation of MyD88 via TLR4 contributes to the liver metastasis of colon cancer cells $[28,29]$. It is still necessary to study changes in TLR expression and its associated signaling pathways in colon cancer, and the effect of TLR2/ 6 and TLR5 on the promotion of drug resistance and metastasis in colon cancer cells is unknown. In this study, enhanced TLR2/6 and TLR5 expression in chemoresistant colon cancer cells reduced the levels of miR-125b-5p. Modification of TLR expression and the related downregulation of miR-125b-5p are causes of Sp1 induction in drug-resistant cancer cells. Sp1-mediated activation of CD248 in colon cancer cells modulated drug resistance and cancer metastasis. These results suggest that altering TLR expression and inducing CD248 in colorectal cancer cells are expected to be important predictors of drug resistance and metastasis (Fig. 6E).

Several studies have reported that the detection of changes in circulating miRNAs might be a promising marker for diagnosing and predicting clinical outcomes in various diseases, including cancer.10, 11 miR-100 and miR-125b expression levels were significantly lower in colorectal cancer tissues with lymph node metastases than in those without metastases [37]. In addition, the high miR125b expression group exhibited a significantly worse prognosis than the low expression group [17], and the level of miR-125b was increased in patients with locally advanced rectal cancer who did not respond to preoperative chemo-radiotherapy [38]. These results suggest that miR-125b could be a promising target for treatment and a marker to judge the effectiveness of a treatment. Based on these controversial studies, the clinical use and role of miR-125b in colon cancer need to be established because colon cancer recurrence and metastasis could potentially be confirmed in a relatively high number of patients. First, we investigated which mechanism altered the expression of miR-125b and what changes in colon cancer cells caused a reduction in miR-125b expression. In this study, the levels of miR-125b-5p in drugresistant colon cancer cells decreased. Gene silencing of either TLR2/6 or TLR5 using siRNA not only upregulated miR-125b-5p but also prevented the migration and expression of both CD248 and drug resistance-related proteins in chemoresistant cancer cells. These results suggest that metastatic or drugresistant colon cancer cells acquire TLR modifications, leading to miR-125b-5p downregulation and 
CD248 upregulation, and detecting changes in TLR expression and miR-125b-5p level in cancer cells is important to evaluate the possibility of metastasis.

Posttranscriptional regulation of Sp1 may be expected to play a key role in the development and progression of cancer. Sp1 overexpression is associated with poor prognosis in various cancers and influences several oncogenes and tumor suppressor genes $[18,19]$. However, the role of Sp1 and its underlying mechanism in controlling the expression of $\mathrm{Sp} 1$ in colon cancer is not yet understood. Since Sp1 is a putative target of miR-125b-5p, the binding of specific ligands to TLR2/ 6 or TLR5 resulted in the activation of Sp1 and CD248 with the downregulation of miR-125b-5p, whereas the Sp1-miR-125b-5p protector effectively alleviated the downregulation of Sp1 and CD248 in chemoresistant colon cancer cells transfected with miR-125b-5p mimic. Furthermore, treating chemoresistant colon cancer cells with fibronectin, a ligand for CD248, enhanced the migratory and invasive activities of these cells. These results suggest that miR-125b-5p downregulation due to modified TLR expression contributes to the induction of Sp1/CD248-mediated drug resistance and metastasis. Hypoxia upregulates the expression of Sp1-dependent glycolysis-related proteins, leading to increases in the aberrant metabolism and invasive activity of cancer cells $[19,20]$. In this study, chemoresistant colon cancer cells enhanced the expression of glycolysis- and de novo lipogenesis-related enzymes. However, Sp1 or CD248 gene silencing with siRNA failed to attenuate the production of lactate and fatty acids in drug-resistant colon cancer cells (data not shown). These results suggest that the Sp1/CD248-mediated signaling pathway has no effect on metabolic changes in colon cancer cells after anticancer chemotherapy. Further investigations may reveal the role of modified TLR expression in the metabolism of drug-resistant cancer cells.

Anticancer drug therapy inevitably leads to the generation of resistant cells, and diagnosing and treating resistant cells are important for the survival of cancer patients. However, there has been no specific way to detect the development of drug-resistant cancer cells until now. CD248 is usually detected in the stromal compartments of colon cancer, and high miR-125b expression results in larger tumor sizes and more frequent tumor invasion $[8,17]$. However, miR-125b-5p expression was decreased in drug-resistant colon cancer cells generated after anticancer chemotherapy, resulting in the upregulation of Sp1mediated CD248 expression in the present study.

\section{Conclusions}

In summary, our study provides experimental information on the relationship between miR-125b-5p and the downstream Sp1-mediated CD248 signaling pathway in TLR-modified drug-resistant colorectal cancer cells. These results also suggest that monitoring the changes in TLR, CD248, and miR-125b-5p expression after chemotherapy is critical for detecting early metastasis and treating advanced colon cancer.

\section{Abbreviations}


EMT: epithelial-mesenchymal transition

FuR: 5-fluorouracil-resistant

LPS: lipopolysaccharide

MDR: multidrug resistance

miRNA: microRNA

MRP: multidrug resistance-associated protein

NF-кB: nuclear factor-кB

OxR: oxaliplatin-resistant

qRT-PCR: quantitative real-time polymerase chain reaction

siRNA: small interfering RNA

Sp1: Specificity protein 1

TLR: Toll-like receptor

\section{Declarations}

\section{Acknowledgments}

Not applicable

\section{Authors' contributions}

GBP carried out all of the experiments and analyses in this study. DK contributed to the conception and design of the study and wrote the manuscript. GBP and DK elaborated study design, coordinated the research and critically revised the manuscript.

\section{Funding}

This work was supported by Basic Science Research Program through the National Research Foundation of Korea (NRF) funded by the Ministry of Education (NRF-2018R1D1A1B07040382) and the National Research Foundation of Korea (NRF) funded by the Korea government (Ministry of Science and ICT, MIST) (NRF-2018R1C1B6002381). 


\section{Availability of data and materials}

The datasets used and/or analyzed during the current study are available from the corresponding author on reasonable request.

\section{Ethics approval and consent to participate}

The study protocol was approved by the Human Research Ethics Committee of Inje University College of medicine and all experiments were performed in accordance with the ethical guidelines of Institutional Review Board.

\section{Consent for publication}

Not applicable

\section{Competing interests}

The authors declare that they have no competing interests.

\section{References}

1. Bagley RG, Weber W, Rouleau C, Yao M, Honma N, Kataoka S, Ishida I, Roberts BL, Teicher BA. Human mesenchymal stem cells from bone marrow express tumor endothelial and stromal markers. Int $\mathrm{J}$ Oncol. 2009;34(3):619-27.

2. Rmali KA, Puntis MC, Jiang WG. Prognostic values of tumor endothelial markers in patients with colorectal cancer. World J Gastroenterol. 2005;11(9):1283-6.

3. Davies G, Cunnick GH, Mansel RE, Mason MD, Jiang WG. Levels of expression of endothelial markers specific to tumour-associated endothelial cells and their correlation with prognosis in patients with breast cancer. Clin Exp Metastasis. 2004;21(1):31-7.

4. Simonavicius N, Robertson D, Bax DA, Jones C, Huijbers IJ, Isacke CM. Endosialin (CD248) is a marker of tumor-associated pericytes in high-grade glioma. Mod Pathol. 2008;21(3):308-15.

5. Nanda A, Karim B, Peng Z, Liu G, Qiu W, Gan C, Vogelstein B, St Croix B, Kinzler KW, Huso DL. Tumor endothelial marker 1 (Tem1) functions in the growth and progression of abdominal tumors. Proc Natl Acad Sci U S A. 2006;103(9):3351-6. 
6. Diaz LA Jr, Coughlin CM, Weil SC, Fishel J, Gounder MM, Lawrence S, Azad N, O'Shannessy DJ, Grasso L, Wustner J, Ebel W, Carvajal RD. A first-in-human phase I study of MORAb-004, a monoclonal antibody to endosialin in patients with advanced solid tumors. Clin Cancer Res. 2015;21(6):1281-8.

7. Bagley RG. Endosialin: from vascular target to biomarker for human sarcomas. Biomark Med. 2009;3(5):589-604.

8. Bagley RG, Honma N, Weber W, Boutin P, Rouleau C, Shankara S, Kataoka S, Ishida I, Roberts BL, Teicher BA. Endosialin/TEM 1/CD248 is a pericyte marker of embryonic and tumor neovascularization. Microvasc Res. 2008;76(3):180-8.

9. Bartel DP. MicroRNAs: genomics, biogenesis, mechanism, and function. Cell. 2004;116(2):281-97.

10. Danese E, Minicozzi AM, Benati M, Paviati E, Lima-Oliveira G, Gusella M, Pasini F, Salvagno GL, Montagnana M, Lippi G. Reference miRNAs for colorectal cancer: analysis and verification of current data. Sci Rep. 2017;7(1):8413.

11. Ng EK, Chong WW, Jin H, Lam EK, Shin VY, Yu J, Poon TC, Ng SS, Sung JJ. Differential expression of microRNAs in plasma of patients with colorectal cancer: a potential marker for colorectal cancer screening. Gut. 2009;58(10):1375-81.

12. Shen J, Stass SA, Jiang F. MicroRNAs as potential biomarkers in human solid tumors. Cancer Lett. 2013;329(2):125-36.

13. Schwarzenbach H, Nishida N, Calin GA, Pantel K. Clinical relevance of circulating cell-free microRNAs in cancer. Nat Rev Clin Oncol. 2014;11(3):145-56.

14. Hollis M, Nair K, Vyas A, Chaturvedi LS, Gambhir S, Vyas D. MicroRNAs potential utility in colon cancer: Early detection, prognosis, and chemosensitivity. World J Gastroenterol. 2015;21(27):828492.

15. Mohammadi A, Mansoori B, Baradaran B. The role of microRNAs in colorectal cancer. Biomed Pharmacother. 2016;84:705-713.

16. Ju J. miRNAs as biomarkers in colorectal cancer diagnosis and prognosis. Bioanalysis. 2010;2(5):901-6.

17. Nishida N, Yokobori T, Mimori K, Sudo T, Tanaka F, Shibata K, Ishii H, Doki Y, Kuwano H, Mori M. MicroRNA miR-125b is a prognostic marker in human colorectal cancer. Int J Oncol. 2011;38(5):1437-43.

18. Koizume S, Miyagi Y. Diverse Mechanisms of Sp1-Dependent Transcriptional Regulation Potentially Involved in the Adaptive Response of Cancer Cells to Oxygen-Deficient Conditions. Cancers (Basel). 2015;8(1).

19. Beishline K, Azizkhan-Clifford J. Sp1 and the 'hallmarks of cancer'. FEBS J. 2015;282(2):224-58.

20. Ohradanova A, Gradin K, Barathova M, Zatovicova M, Holotnakova T, Kopacek J, Parkkila S, Poellinger L, Pastorekova S, Pastorek J. Hypoxia upregulates expression of human endosialin gene via hypoxia-inducible factor 2 . Br J Cancer. 2008;99(8):1348-56. 
21. Rakoff-Nahoum S, Medzhitov R. Toll-like receptors and cancer. Nat Rev Cancer. 2009;9(1):57-63.

22. Li TT, Ogino S, Qian ZR. Toll-like receptor signaling in colorectal cancer: carcinogenesis to cancer therapy. World J Gastroenterol. 2014;20(47):17699-708.

23. Gao K, Liang Q, Zhao ZH, Li YF, Wang SF. Synergistic anticancer properties of docosahexaenoic acid and 5-fluorouracil through interference with energy metabolism and cell cycle arrest in human gastric cancer cell line AGS cells. World J Gastroenterol. 2016;22(10):2971-80.

24. Yang AD, Fan F, Camp ER, van Buren G, Liu W, Somcio R, Gray MJ, Cheng H, Hoff PM, Ellis LM. Chronic oxaliplatin resistance induces epithelial-to-mesenchymal transition in colorectal cancer cell lines. Clin Cancer Res. 2006;12(14 Pt1):4147-53.

25. Park GB, Kim D. MicroRNA-503-5p Inhibits the CD97-Mediated JAK2/STAT3 Pathway in Metastatic or Paclitaxel-Resistant Ovarian Cancer Cells. Neoplasia. 2019;21(2):206-215.

26. Park GB, Kim YS, Lee HK, Yang JW, Kim D, Hur DY. ASK1/JNK-mediated TAp63 activation controls the cell survival signal of baicalein-treated EBV-transformed B cells. Mol. Cell. Biochem. 2016;412(12):247-58.

27. Park GB, Chung YH, Gong JH, Jin DH, Kim D. GSK-3ß-mediated fatty acid synthesis enhances epithelial to mesenchymal transition of TLR4-activated colorectal cancer cells through regulation of TAp63. Int. J. Oncol. 2016;49(5):2163-72.

28. Gilmore TD. Introduction to NF-kappaB: players, pathways, perspectives. Oncogene. 2006;25(51):6680-4.

29. Ridnour LA, Cheng RY, Switzer CH, Heinecke JL, Ambs S, Glynn S, Young HA, Trinchieri G, Wink DA. Molecular pathways: toll-like receptors in the tumor microenvironment-poor prognosis or new therapeutic opportunity. Clin Cancer Res. 2013;19(6):1340-6.

30. Tili E, Michaille JJ, Cimino A, Costinean S, Dumitru CD, Adair B, Fabbri M, Alder H, Liu CG, Calin GA, Croce CM. Modulation of miR-155 and miR-125b levels following lipopolysaccharide/TNF-alpha stimulation and their possible roles in regulating the response to endotoxin shock. J Immunol. 2007;179(8):5082-9.

31. MacFadyen J, Savage K, Wienke D, Isacke CM. Endosialin is expressed on stromal fibroblasts and CNS pericytes in mouse embryos and is downregulated during development. Gene Expr Patterns. 2007;7(3):363-369.

32. Rouleau C, Curiel M, Weber W, Smale R, Kurtzberg L, Mascarello J, Berger C, Wallar G, Bagley R, Honma N, et al . Endosialin protein expression and therapeutic target potential in human solid tumors: sarcoma versus carcinoma. Clin Cancer Res. 2008;14(22):7223-36.

33. Becker R, Lenter MC, Vollkommer T, Boos AM, Pfaff D, Augustin HG, Christian S. Tumor stroma marker endosialin (Tem1) is a binding partner of metastasis-related protein Mac-2 BP/90K. FASEB J. 2008;22(8):3059-67.

34. Maia M, DeVriese A, Janssens T, Moons M, Lories RJ, Tavernier J, Conway EM. CD248 facilitates tumor growth via its cytoplasmic domain. BMC Cancer. 2011;11:162. 
35. O'Shannessy DJ, Somers EB, Chandrasekaran LK, Nicolaides NC, Bordeaux J, Gustavson MD. Influence of tumor microenvironment on prognosis in colorectal cancer: Tissue architecturedependent signature of endosialin (TEM-1) and associated proteins. Oncotarget. 2014;5(12):398395.

36. Krol J, Loedige I, Filipowicz W. The widespread regulation of microRNA biogenesis, function and decay. Nat Rev Genet. 2010;11(9):597-610.

37. Fujino Y, Takeishi S, Nishida K, Okamoto K, Muguruma N, Kimura T, Kitamura S, Miyamoto H, Fujimoto A, Higashijima J, Shimada M, Rokutan K, Takayama T. Downregulation of microRNA$100 /$ microRNA-125b is associated with lymph node metastasis in early colorectal cancer with submucosal invasion. Cancer Sci. 2017;108(3):390-97.

38. D'Angelo E, Fassan M, Maretto I, Pucciarelli S, Zanon C, Digito M, Rugge M, Nitti D, Agostini M. Serum $\mathrm{miR}-125 \mathrm{~b}$ is a non-invasive predictive biomarker of the pre-operative chemoradiotherapy responsiveness in patients with rectal adenocarcinoma. Oncotarget. 2016;7(19):28647-57.

\section{Figures}


Figure 1
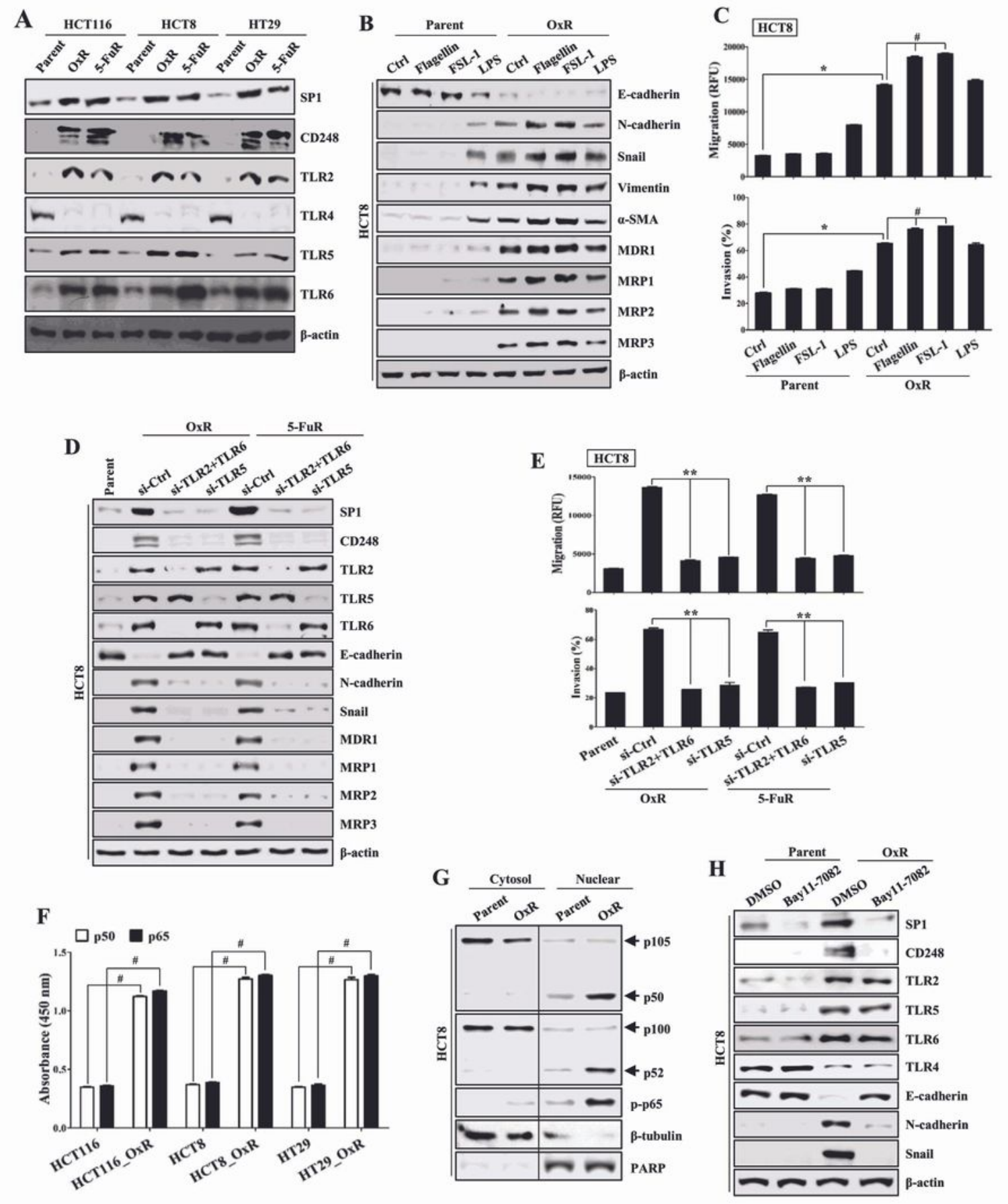

\section{Figure 1}

TLR2/6 and TLR5-mediated NF-KB activation in drug-resistant colon cancer cells induces Sp1 and CD248 expression and promotes metastasis. (A) Total protein from each group was subjected to Western blot analysis with the indicated antibodies. (B, C) Cells $(1.5 \times 105 /$ well $)$ were seeded into 6-well plates and cultured overnight. The cells were then cultured in the presence or absence of TLR agonists $(100 \mathrm{ng} / \mathrm{ml}$ flagellin, $100 \mathrm{ng} / \mathrm{ml} \mathrm{FSL-1,} \mathrm{or} 500 \mathrm{ng} / \mathrm{ml}$ LPS) for $24 \mathrm{~h}$. Sterile distilled water was used as a vehicle 
control. (D, E) Cells were transfected with TLR2, TLR5, TLR6, or control siRNAs for $48 \mathrm{~h}$ prior to experiments. (B, D) Total cell lysates were immunoblotted with the indicated antibodies. $\beta$-Actin served as an internal control, and the data are representative of 3 independent experiments. (C, E) The migratory activity and invasiveness of the cells were detected using a tumor transendothelial migration assay kit and BME cell invasion assay kit, respectively, as described in the Materials and Methods section. *, $p<0.001, * *, p<0.005, \#, p<0.01$ (F) ELISA was used to measure the DNA-binding activity of NF-KB in nuclear extracts. The transcription factor NF-KB p50 combo and p65 combo (in the Kit) served as positive controls for NF-KB activity. The ELISA results are expressed as the relative absorbance. \#, $p<0.01$ (G) Cytosolic extracts (left) and nuclear extracts (right) were examined by Western blot analysis using antibodies against p105/p50, p100/p52 and phospho-p65. A nuclear marker, PARP, and a cytosolic marker, $\beta$-tubulin, were used to assess the purity of each fraction. $(H)$ Cells $(1.5 \times 105 /$ well $)$ were treated with the NF-KB inhibitor Bay11-7082 $(5 \mu \mathrm{M})$ for $24 \mathrm{~h}$. Total protein was subjected to Western blot analysis with the indicated antibodies. Each value in the bar graph is presented as the mean \pm standard deviation (SD). The error bars represent the SD from three independent experiments $(n=3)$, and the immunoblotting data are representative of 3 independent experiments. 
Figure 2

A Position 3141-3147
of Sp1 3' UTR
miR-125b-5p CCACACCGUCUUCCUUCAGGGAU...

B

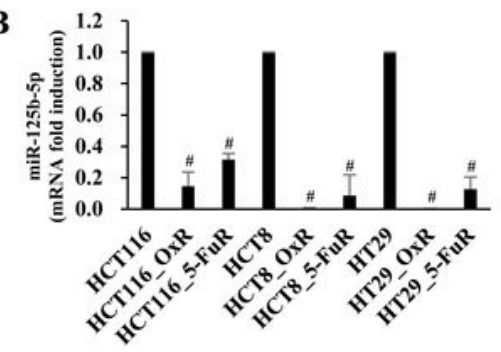

C

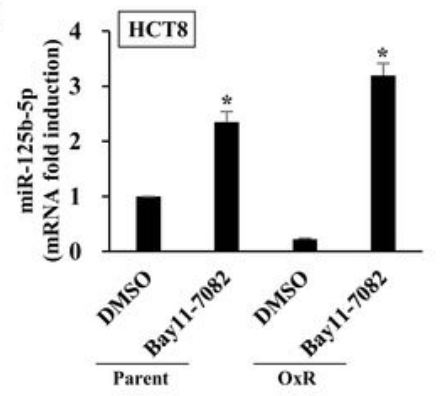

D HCT8
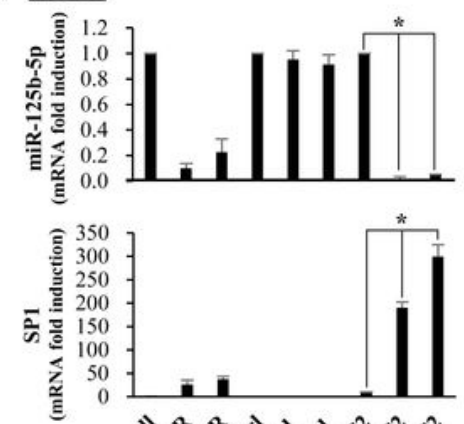

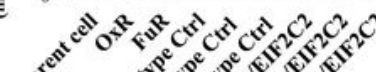

a wis
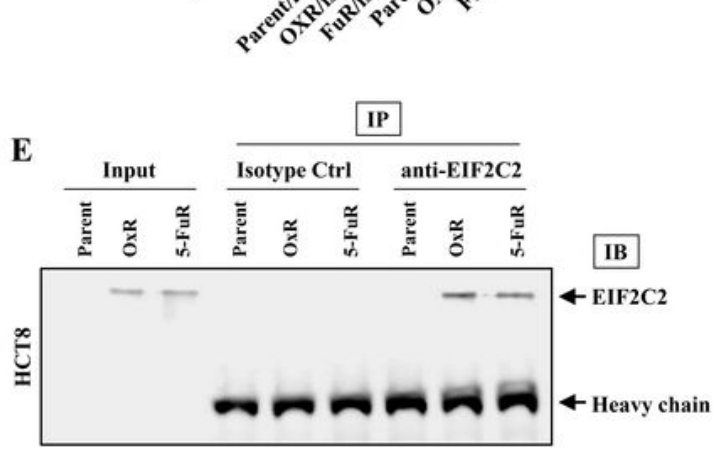

F
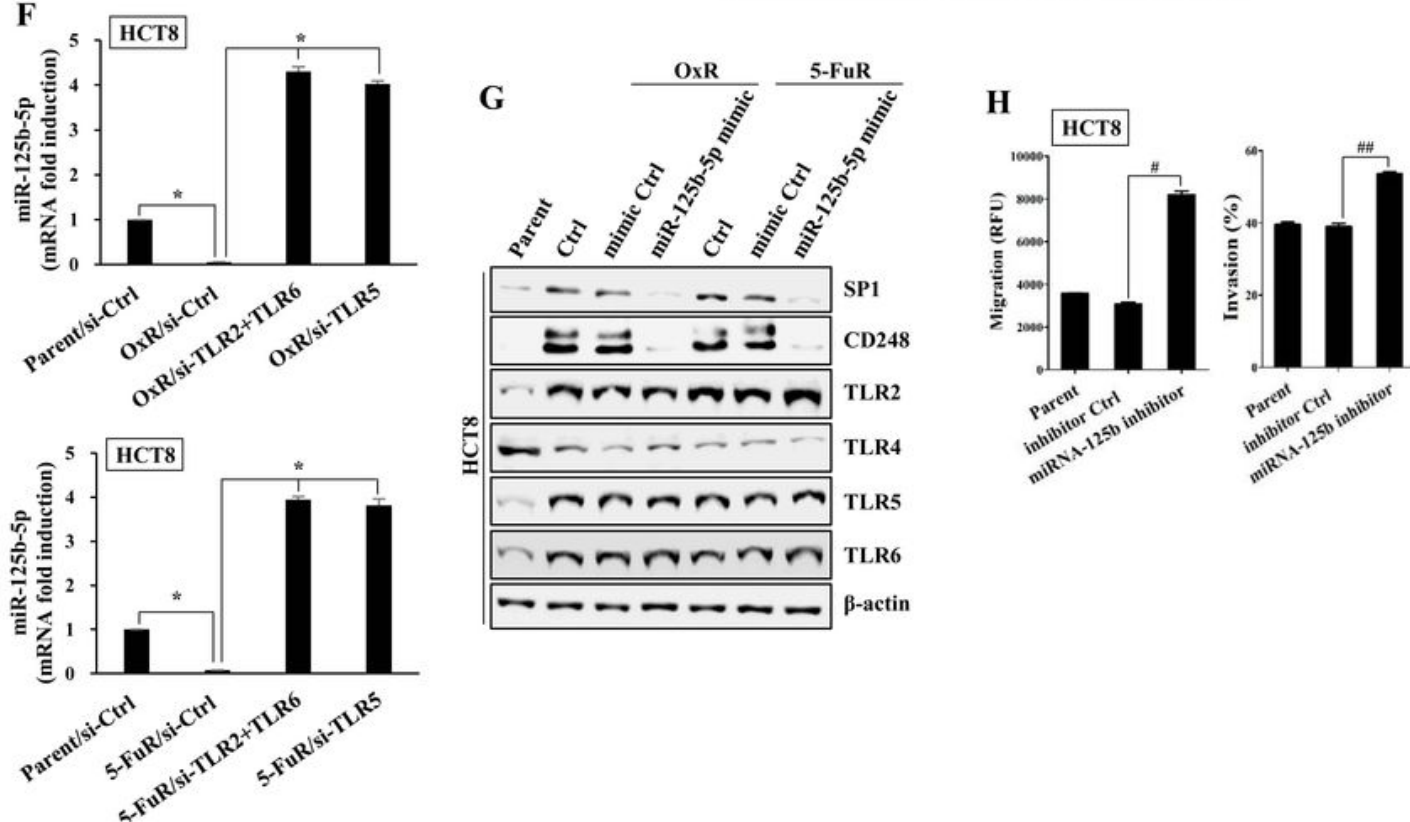
OxR or parent colon cancer cells. *, $p<0.001$ (DMSO vs. Bay11-7082). (D) Cells $(1.5 \times 105 /$ well) were transfected with TLR2, TLR5, TLR6, or control siRNAs for $48 \mathrm{~h}$ prior to measuring miR-125b-5p expression. *, $\mathrm{p}<0.001$ (E) Cells $(1.5 \times 105 /$ well) were transfected with miR-125b-5p mimic or control mimic for $48 \mathrm{~h}$. Total protein was subjected to Western blot analysis with the indicated antibodies. $(\mathrm{F})$ HCT 8 parent cells $(1.5 \times 105 /$ well $)$ were transfected with the miR-125b-5p inhibitor for $48 \mathrm{~h}$ before measuring migratory and invasive activities. \#, $p<0.01, \# \#, p<0.05$. Each value in the bar graph is presented as the mean \pm standard deviation (SD). The error bars represent the SD from three independent experiments $(n=3)$, and the immunoblotting data are representative of 3 independent experiments. 
Figure 3
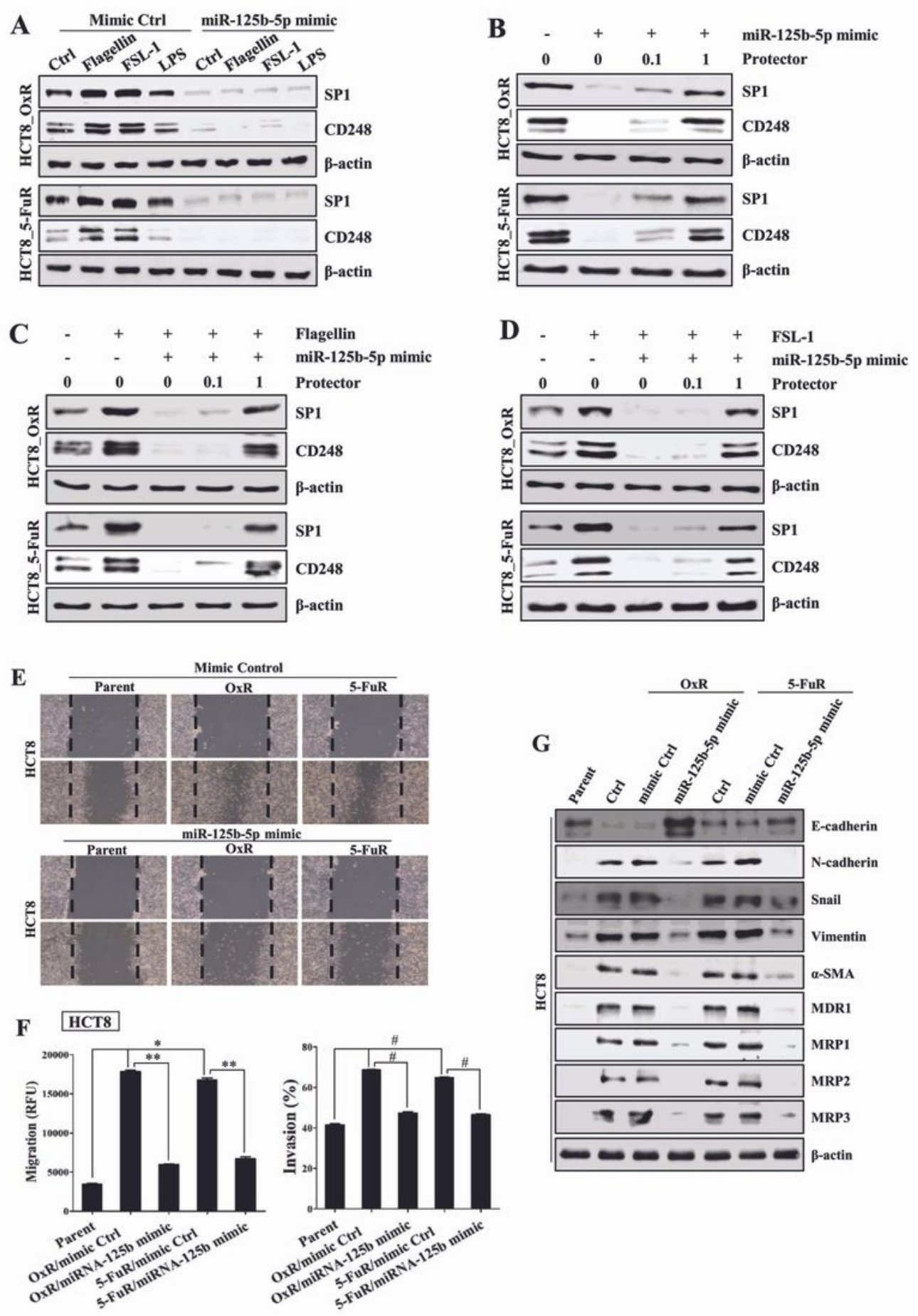

\section{Figure 3}

Sp1 is a direct target of miR-125b-5p and controls the metastasis of drug-resistant colon cancer cells. Cells $(1.5 \times 105 /$ well $)$ were seeded into 6 -well plates and incubated overnight. (A) Then, the cells were transfected with miR-125b-5p mimic or mimic control for $48 \mathrm{~h}$. (B) Cells were also transfected with miR125b-5p mimic and treated with TLR agonists (100 ng/ml flagellin, $100 \mathrm{ng} / \mathrm{ml} \mathrm{FSL-1,} \mathrm{or} 500 \mathrm{ng} / \mathrm{ml} \mathrm{LPS}$ ) for 24 h. (C, D) Cells were transfected with different concentrations of Sp1-miR-125b-5p target protector 
$(0 \sim 1 \mu \mathrm{M})$ together with miR-125b-5p mimics, followed by the administration of TLR agonists $(100 \mathrm{ng} / \mathrm{ml}$ flagellin or $100 \mathrm{ng} / \mathrm{ml} \mathrm{FSL-1)}$ for $24 \mathrm{~h}$. Sterile distilled water was used as a vehicle control. Total cell lysates were immunoblotted with the indicated antibodies. $\beta$-Actin served as an internal control. (E) Cell motility was modulated by miR-125b-5p expression as measured by a wound healing assay. Cells were wounded $(0 \mathrm{~h})$ and maintained for $24 \mathrm{~h}$ in complete medium. The dotted lines indicate the edges of the wounds. $(\mathrm{F})$ The migratory activity and invasiveness of the cells were detected by a tumor transendothelial migration assay kit and BME cell invasion assay kit, respectively, as described in the Materials and Methods section. ${ }^{*}, p<0.005 ;{ }^{* *}, p<0.01 ; \#, p<0.05$. (G) Cells $(1.5 \times 105 /$ well) were transfected with miR-125b-5p mimic or control mimic for $48 \mathrm{~h}$ to analyze the changes in mesenchymal markers and drug-resistant related proteins. Total protein was subjected to Western blot analysis with the indicated antibodies. Each value in the bar graph is presented as the mean \pm standard deviation (SD). The error bars represent the SD from three independent experiments $(n=3)$, and the immunoblotting data are representative of 3 independent experiments.

\section{Figure 4}
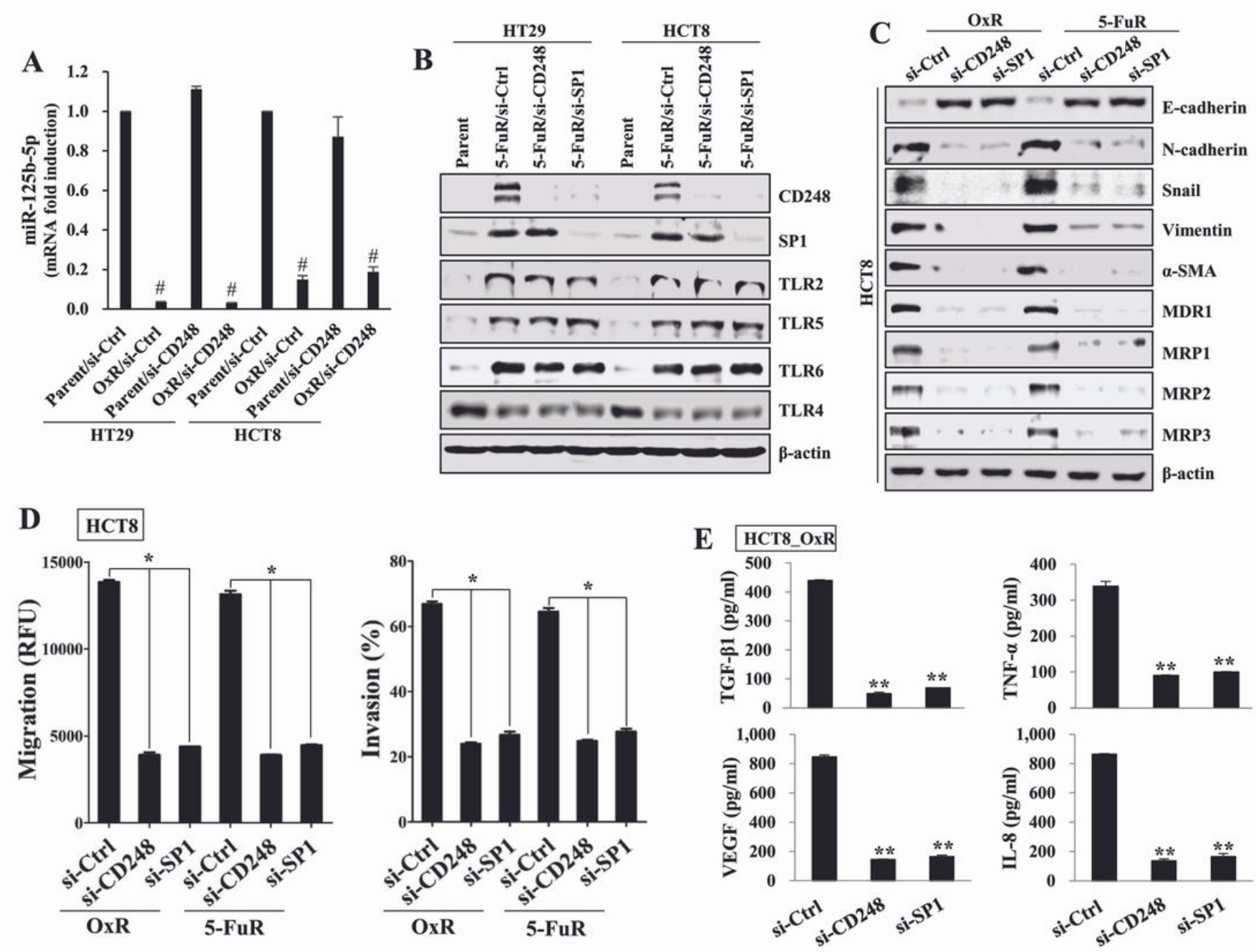

E HCT8_OxR
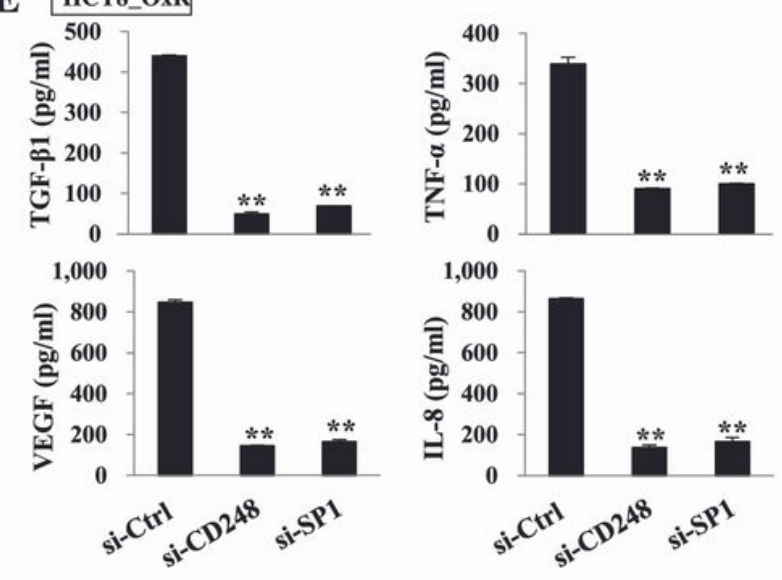

Figure 4 
Increased CD248 expression modulates the metastasis of TLR-modified colon cancer cells. Cells ( $1.5 \times$ 105/well) were transfected with CD248, Sp1, or control siRNAs for $48 \mathrm{~h}$ prior to experiments. (A) Quantitative real-time RT-PCR ( $q P C R$ ) was performed to determine the relative expression of miR-125b-5p. $\#, p<0.01$ (parent cells vs. chemoresistant cells). $(B, C)$ Total protein was subjected to Western blot analysis with the indicated antibodies. (D) The migratory activity and invasiveness of the cells were detected by a tumor transendothelial migration assay kit and BME cell invasion assay kit, respectively, as described in the Materials and Methods section. Each value is presented as the mean \pm standard deviation (SD). The error bars represent the SD from three independent experiments $(n=3) *, p<0.001$. (E) The concentrations of TGF- $\beta 1$, TNF- $\alpha$, VEGF, and IL- 8 in the cell culture supernatants were quantified by ELISA. Each value is presented as the mean \pm standard deviation (SD). The error bars represent the SD from three independent experiments $(n=3) * \star, p<0.005$ (cells transfected with control siRNA vs. cells transfected with the indicated siRNA). 
Figure 5

A
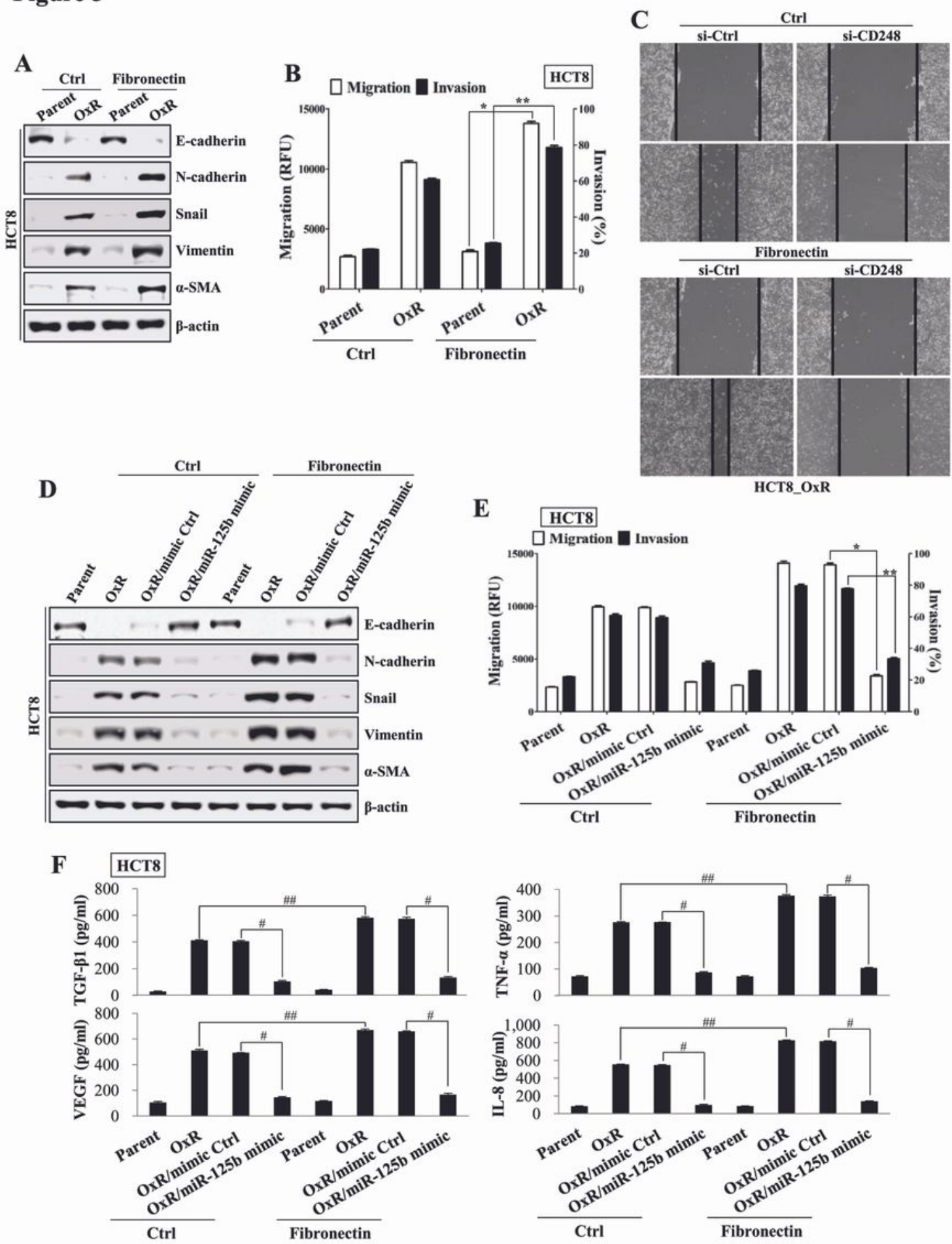

\section{Figure 5}

Stimulation with fibronectin, a CD248 ligand, increases the mesenchymal markers and migratory activity of drug-resistant colon cancer cells. Cells were seeded at $1.5 \times 105 /$ well in fibronectin-coated 6-well plates and cultured overnight. (A, D) Total protein was subjected to Western blot analysis with the indicated antibodies. (C) Cells were transfected with si-CD248, si-Sp1, and si-control. Then, the cells were scratched ( $0 \mathrm{~h}$ ) and maintained in complete medium for $24 \mathrm{~h}$. The dotted lines indicate the edges of the wounds. (B, 
E) The migratory activity and invasiveness of the cells were detected by a tumor transendothelial migration assay kit and BME cell invasion assay kit, respectively, as described in the Materials and Methods section. Each value is presented as the mean \pm standard deviation (SD). The error bars represent the SD from three independent experiments $(n=3) *, p<0.001, * *, p<0.005$. (F) The concentrations of TGF$\beta 1$, TNF-a, VEGF, and IL-8 in the culture supernatants were quantified by ELISA. Each value is presented as the mean \pm standard deviation (SD). The error bars represent the SD from three independent experiments $(n=3) \#, p<0.01, \# \#, p<0.05$.

Figure 6
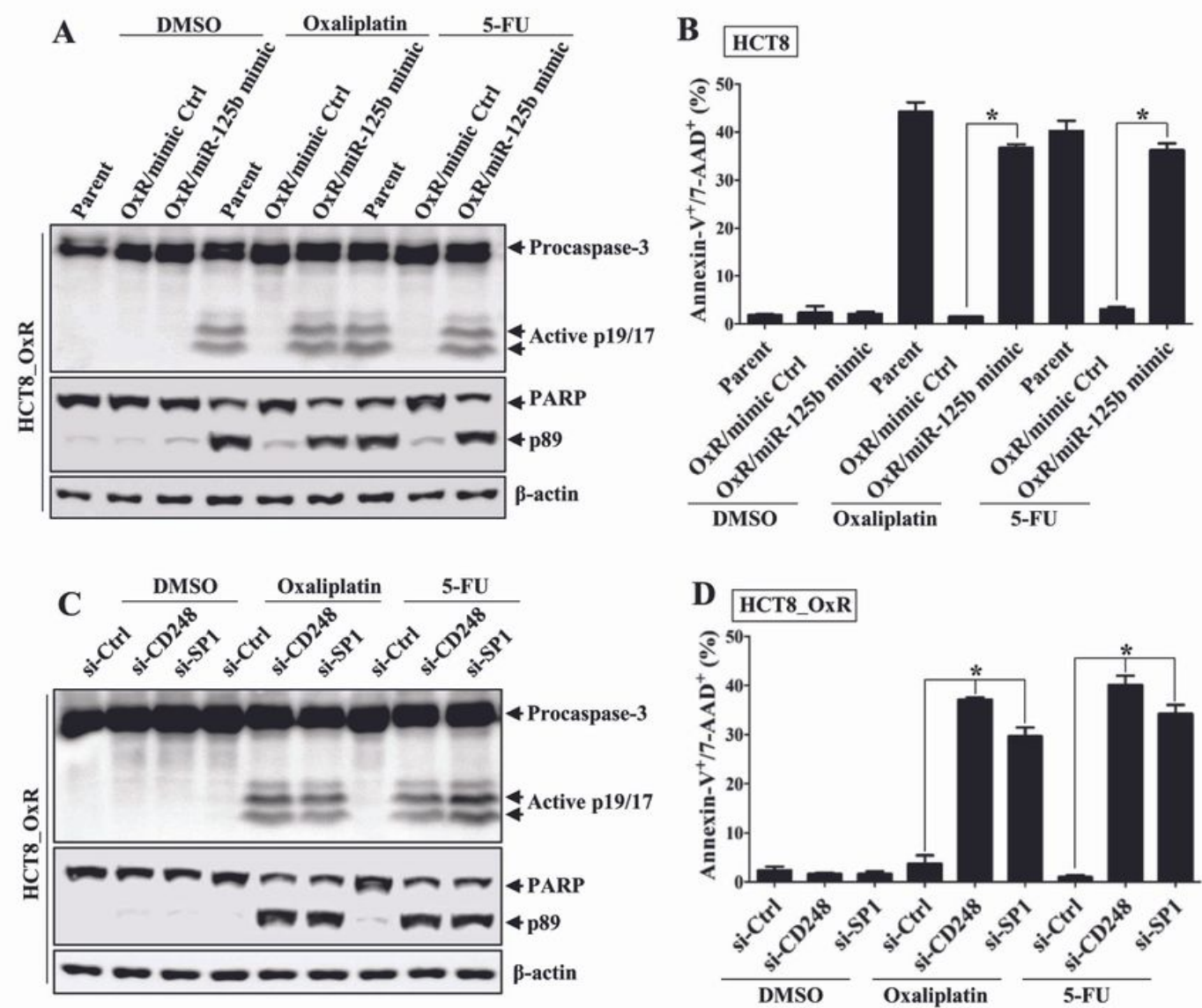

$\mathbf{E}$

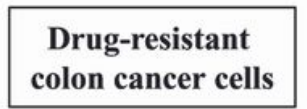

TLR5/2/6† (TLR4 $\downarrow$ )

NF-кB

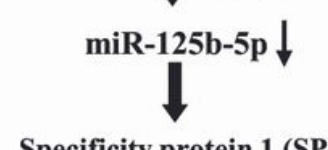

Specificity protein 1 (SP1) $\uparrow$
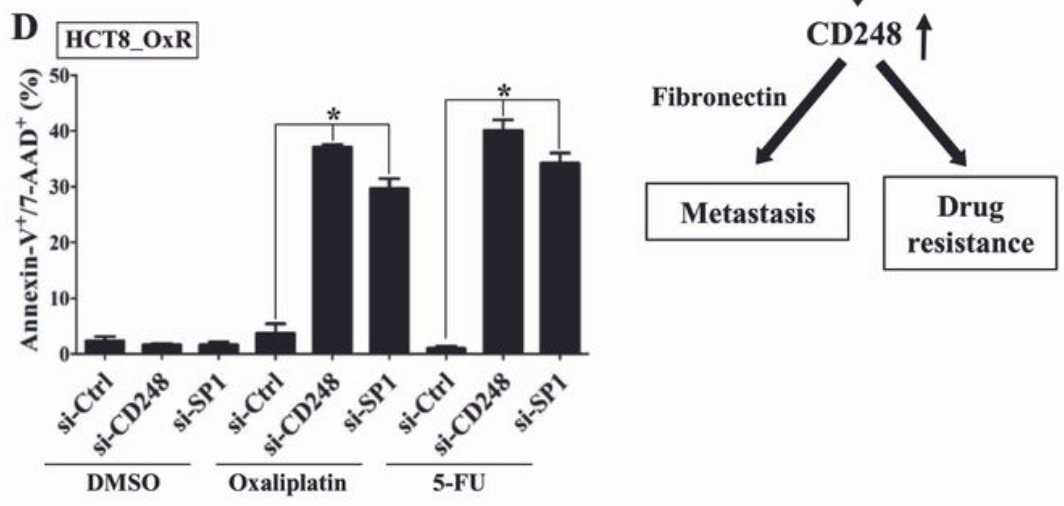

\section{Figure 6}

Upregulated miR-125b-5p expression and downregulated CD248 expression promote the cell death of chemoresistant colon cancer cells. (A, B) Cells $(1.5 \times 105 /$ well) were transfected with miR-125b mimic or mimic control for $36 \mathrm{~h}$ and then treated with $20 \mu \mathrm{M}$ oxaliplatin or $20 \mu \mathrm{M} \mathrm{5-Fu} \mathrm{for} 24 \mathrm{~h}$. DMSO was used as a vehicle control. (C, D) Cells $(1.5 \times 105 /$ well) were transfected with CD248, Sp1, or control siRNAs for $36 \mathrm{~h}$ and then exposed to $20 \mu \mathrm{M}$ oxaliplatin or $20 \mu \mathrm{M} 5$-Fu for $24 \mathrm{~h}$. (A, C) Total protein was subjected to Western blot analysis with the indicated antibodies. $(B, D)$ The percentage of apoptotic cells was estimated by annexin-V/7-AAD staining. The number of late-stage apoptotic cells (annexin-V+/7-AAD+) was calculated by flow cytometry. Each value is presented as the mean \pm standard deviation (SD). The error bars represent the SD from three independent experiments $(n=3)$ *, $p<0.001$. (E) Schematic diagram 
of the intracellular signaling pathway in drug-resistant human colon cancer cells. TLR2/6 and TLR5 upregulation in drug-resistant colon cancer cells contributed to the downregulation of miR-125b-5p and Sp1-mediated upregulation of CD248 by activating NF-KB signaling. Drug resistance-induced increases in CD248 expression enhance the metastatic potential of colon cancer cells. Our findings suggest that changes in miR-125b-5p levels play an important role in Sp1-mediated CD248 expression and the development of drug resistance in colon cancer cells with mutated TLR.

\section{Supplementary Files}

This is a list of supplementary files associated with this preprint. Click to download.

- supplement1.docx 